\section{Выводы:}

1. В хорошем районе за период 2006-2014 гг. с помощью быстрых уведомлений было зарегистрировано 1416 укусов клещей, и 50,02\% из них были идентифицированы по типу в лаборатории ОИЗ Добрич и ОИЗ-Варна.

2. Системно, 4 типа клещей - Ixodes Ricinus $76,12 \%$, Hyalomma marginatum - 11,93\%, Dermacentor marginatus - 8,0\%, Rhipicephalus sanguineus 3,93\%. Не определяется Rhipicephalus bursa и другими видами.

3. Сезонная динамика представляет собой год 11 месячный период для Dermacentor marginatus, 8 для Ixodes Ricinus и 7 месяцев для Hyalomma marginatum, Rhipicephalus sanguineus.

4. Хорошая организация для отчетности и отправки тиков, которые будут назначены в Каварна Муниципалитет, Генерал. Тошево, Балчик и Добрич.

\section{Литература:}

1.Валканова Н., С. Станева, А. Костова, Д. Стойчева, Т. Панайтова, Ц. Паунов, Р. Константинов, Р. Маринова, Клерчевские популяции в Варне, Добриче и Разградском районе за 2002-2003 годы, Бюллетень ADD, 1-4 2004, 63-71.

2. Валканова Н., Ц. Паунов, Р. Константинов, М. Ненова, П. Манолов, М. Денева, Е. Ангелов, А. Костова, Д. Стойчева, Т. Панайотова, Сезонная динамика и разнообразие популяций крыс в Варне и Добричском районе., Бюллетень ADD, 3-4, 2001, 63-71

3. eur-lex.europa.eu

4.http: //www.msd-animal-health.bg/

5. http://frontline.bg.merial.com/

6. http://news.ibox.bg/news/id_415348547

7.http: //im-control.eu/vidove-kurleji.html

8. http://provadiadnes.com/news.php?id=2291

9.http: //tickfree.eu/

10.http: //posredniknews.com/site/component/content/article/

11. http://smolyanpress.net/

12. http://santevita-bg.com/

УДК. 613.62

АНАЛИЗ ЗАБОЛЕВАЕМОСТИ С ВРЕМЕННОЙ УТРАТОЙ ТРУДОСПОСБНОСТИ НА ПРЕДПРИЯТИЯХ МАШИНОСТРОЕНИЯ Г. НАБЕРЕЖНЫЕ ЧЕЛНЫ В 2008-2018 ГГ.

\title{
ANALYSIS OF MORBIDITY WITH TEMPORARY DISABILITY AT MACHINE-BUILDING ENTERPRISES IN NABEREZHNYE CHELNY IN 2008-2018
}

Нагимзянов А.А., Закирова А.Б.

ООО «Медицинское объединение "Спасение» 420059, г. Казань, ул. Назарбаева, д. 47

DOI: 10.31618/ESU.2413-9335.2019.1.60.35-39

Nagimzyanov A.A., Zakirova A.B., LLC «Medical Association «Spasenie», 420059, Kazan, Nazarbaeva str., d. 47

\section{АННОТАЦИЯ.}

Цель анализа проследить одиннадцатилетнюю динамику заболеваемости с временной утратой трудоспособности на предприятиии определить факторы на нее влияющие.

\section{ABSTRACT}

The Purpose of the analysis is to trace the eleven-year dynamics of morbidity with temporary disability in the enterprise to determine the factors affecting it.

Ключевые слова: здравпункты, заболеваемость с временной утратой трудоспособности, часто и длительно болеющие.

Keywords: first-aid post, temporary disability, morbidity with temporary disability, often and long-term ill.

ООО «Медицинское объединение «Спасение» в рамках соглашения с предприятием среднего машиностроения, расположенного в г. Набережные Челны, оказывает работникам предприятия медицинские услуги в здравпунктах на территории «основных» и «неосновных» (дочерних) предприятий.
На территории предприятия действуют семь здравпунктов с круглосуточной формой обслуживания работников численностью 23105 человек. 
Таблица 1.Численность здравпунктов и режим оказания медицинских услуг

\begin{tabular}{|c|c|c|c|}
\hline №№ & «Основные» предприятия & $\begin{array}{c}\text { Количество } \\
\text { здравпунктов }\end{array}$ & $\begin{array}{c}\text { Режим оказания меди- } \\
\text { цинских услуг }\end{array}$ \\
\hline 1. & Литейный завод & 2 & круглосуточно \\
\hline 2. & Кузнечный завод & 2 & круглосуточно \\
\hline 3. & Прессово-рамный завод & 1 & круглосуточно \\
\hline 4. & Завод двигателей & 1 & круглосуточно \\
\hline 5. & Автомобильный завод & 1 & круглосуточно \\
\hline 6. & Всего & 7 & \\
\hline
\end{tabular}

Здравпункты работают по принципу сметного финансирования и осуществляют свою деятельность согласно приказа МЗ РФ от 13 ноября 2012 года № 911н «Об утверждении порядка оказания медицинской помощи при острых и хронических профессиональных заболеваниях».

Ключевые показатели деятельности здравпунктов по листам нетрудоспособности, которые отслеживает и анализирует медицинская служба:

1. Заболеваемость с временной утратой трудоспособности;

2. Группы часто и длительно болеющих работников;

Учет листов трудоспособности производился при помощи программы для ЭВМ «Автоматизированная информационная система «Спасение». Свидетельство о госрегистрации №2014617335 от 17.07.2014 г.

І. Заболеваемость с временной утратой трудоспособности (ЗВУТ)

1.1. Общие положения и численность работников. Анализируются случаи, дни нетрудоспособности, среднее время пребывания на листе нетрудоспособности. Учитывая, что показатели рассчитываются на 100 работников, то существенное влияние оказывает динамика среднесписочной численности работников и при аналогичных абсолютных показателях, рассчитываемые относительные показатели могут существенно отличаться.

В связи с этим для более точного выявления тенденций по уровню случаев и дней ЗВУТ анализ произведен за 11 предыдущих лет с учетом дина- мики средней численности работников с применением статистического методов выравнивания динамических рядов (метод укрупнения рядов и метод скользящей средней).

В 2018 году заболеваемость рассчитывалась исходя из численности работников основных предприятий 23105 человек, в т.ч. мужчин 13439 человек и женщин 9307 человека. Динамика по сравнению с 2008 годом снижение на 48,9\% в целом, среди мужчин снижение на $41,5 \%$ и среди женщин на $57,0 \%$.

Дополнительно влияет на расчеты относительных данных ЗВУТ гендерная структура работников - соотношение мужчин и женщин. В 2008 году соотношение мужчин и женщин было 52,3\% к 47,7\%, а в 2018 году - 59,7\% к 40,3\% (Возможно на это повлияли структурные изменения на предприятиях - в связи с переводом специалистов финансово-экономического профиля, с большой долей женщин из «основного» производства в «неосновные» (дочерние) организации, т.е. на «основном» производстве увеличивается доля рабочих профессий, особенно стажированных).

Возрастной состав работников также оказывает влияние. Доля работников старше 50 лет на предприятиях составляет $40,2 \%$, старше $60-8,8 \%$. Именно среди этих возрастных категорий велика доля часто и длительно болеющих (49\% работников из этой возрастной категории с накопленной заболеваемостью).

1.2. Анализ 3ВУТ. Для анализа ЗВУТ взяты сводные показатели по уровням случаев, дней и средней продолжительности 1 случая ЗВУТ с использованием метода укрупнения рядов.

Таблица 2 Уровень случаев ЗВУТ в 2008-2018 гг. (в целом по «основным» предприятиям, на 100 работников)

\begin{tabular}{|c|c|c|c|}
\hline Годы & $\begin{array}{c}\text { Значение, на } 100 \text { ра- } \\
\text { ботников }\end{array}$ & $\begin{array}{c}\text { Темп прироста (сниже- } \\
\text { ния), в \% }\end{array}$ & Метод укрупнения рядов \\
\hline 2008 & 83,88 & - & \multirow{2}{*}{70,2} \\
\hline 2009 & 56,59 & $-32,5$ & \multirow{2}{*}{73,2} \\
\hline 2010 & 77,59 & 37,1 & \multirow{2}{*}{68,9} \\
\hline 2011 & 68,77 & $-11,4$ & \multirow{2}{*}{65,2} \\
\hline 2012 & 64,77 & $-5,8$ & \multirow{2}{*}{62,5} \\
\hline 2013 & 73,14 & 12,9 & 52,7 \\
\hline 2014 & 67,13 & $-8,2$ & \\
\hline 2015 & 63,31 & $-5,7$ & \\
\hline 2016 & 64,72 & 2,2 & \\
\hline 2017 & 60,24 & $-6,9$ & \\
\hline
\end{tabular}


Отмечается снижение случаев ЗВУТ в целом по основным предприятиям на 37,2\% (период 2008-2018 гг.) и на 12,6\% (период 2017-2018 гг.). Общее снижение более наглядно выявляется при использовании метода укрупнения рядов.

Таблица 3 Уровень дней ЗВУТ в 2008-2018 гг.(в целом по «основным» предприятиям, на 100 работников)

\begin{tabular}{|c|c|c|c|}
\hline Годы & $\begin{array}{c}\text { Значение, на } 100 \text { ра- } \\
\text { ботников }\end{array}$ & $\begin{array}{c}\text { Темп прироста (сниже- } \\
\text { ния), в \% }\end{array}$ & \multirow{2}{*}{ Метод укрупнения рядов } \\
\hline 2008 & 1225,85 & - & \multirow{2}{*}{1069,2} \\
\hline 2009 & 912,52 & $-25,6$ & \multirow{2}{*}{1125,1} \\
\hline 2010 & 1175,53 & 28,8 & \multirow{2}{*}{1034,7} \\
\hline 2011 & 1074,75 & $-8,6$ & \multirow{2}{*}{1026,2} \\
\hline 2012 & 980,3 & $-8,8$ & \multirow{2}{*}{1022,7} \\
\hline 2013 & 1089 & 11,1 & 831,51 \\
\hline 2014 & 1055,9 & -3 & $-5,6$ \\
\hline 2015 & 996,43 & 3,4 & $-14,8$ \\
\hline 2017 & 1029,88 & $-14,8$ & \\
\hline
\end{tabular}

Отмечается снижение дней ЗВУТ в целом по основным предприятиям на 32,2\% (период 2008-2018 гг.) и на 14,8\% (период 2017-2018 гг.). Общее снижение более наглядно выявляется при использовании метода укрупнения рядов.

Таблица 4 Уровень средней продолжительности 1 случая ЗВУТ в 2008-2018 гг. (в целом по «основным» предприятиям)

\begin{tabular}{|c|c|c|c|}
\hline Годы & Значение & $\begin{array}{c}\text { Темп прироста (сниже- } \\
\text { ния), в \% }\end{array}$ & Метод укрупнения рядов \\
\hline 2008 & 14,6 & - & \multirow{2}{*}{15,4} \\
\hline 2009 & 16,1 & 10,3 & \multirow{2}{*}{15,4} \\
\hline 2010 & 15,2 & $-5,6$ & \multirow{2}{*}{15} \\
\hline 2011 & 15,6 & 2,6 & \multirow{2}{*}{15,7} \\
\hline 2012 & 15,1 & $-3,2$ & \multirow{2}{*}{16,1} \\
\hline 2013 & 14,9 & $-1,3$ & 12,6 \\
\hline 2014 & 15,7 & 5,4 & \\
\hline 2015 & 15,7 & 0 & 1,3 \\
\hline 2017 & 15,9 & 1,9 & \\
\hline 2018 & 16,2 & $-22,2$ & \\
\hline
\end{tabular}

До 2018 года отмечался рост среднего пребывания на листе нетрудоспособности, но в 2018 году отмечается снижение на 22,2\% (период сравнения 2017 и 2018 гг.) и на 13,7\% (период сравнения 2008 и 2018 гг.). Это говорит о том, что в 2018 году на фоне общего снижения случаев, и дней превалируют более легкие и не длительные формы заболеваний.
Для детального анализа структуры заболеваемости были взяты четыре нозологии (болезни органов кровообращения, болезни органов дыхания, болезни костно-мышечной системы и травмы), которые в 2018 году составляют 78,5\% в структуре случаев и 73,9\% в структуре дней; 
Таблица 5 Уровень случаев ЗВУТ в 2008 и 2018 гг. по ведущим нозологиям (свод по «основным» предприятиям, на 100 работников, в т.ч. мужчин и женщин)

\begin{tabular}{|c|l|c|c|c|}
\hline №№ & \multicolumn{1}{|c|}{ Нозологии } & 2008 г. & 2018 г. & $\begin{array}{c}\text { Темп при- } \\
\text { роста }\end{array}$ \\
\hline 1. & Случаи ЗВУТ (всего) & 83,88 & 52,65 & $-37,2 \%$ \\
\hline 1.1. & Случаи ЗВУТ (среди мужчин) & 86,44 & 50,30 & $-41,8 \%$ \\
\hline 1.2. & Случаи ЗВУТ (среди женщин) & 81,07 & 56,11 & $-30,8 \%$ \\
\hline 2. & Болезни органов кровообращения (всего) & 6,61 & 6,07 & $-8,2 \%$ \\
\hline 2.1. & Болезни органов кровообращения (среди мужчин) & 7,4 & 6,23 & $-15,8 \%$ \\
\hline 2.2. & Болезни органов кровообращения (среди женщин) & 5,74 & 5,83 & $1,6 \%$ \\
\hline 3. & Болезни органов дыхания (всего) & 30,47 & 16,29 & $-46,5 \%$ \\
\hline 3.1. & Болезни органов дыхания (среди мужчин) & 30,83 & 14,06 & $-54,4 \%$ \\
\hline 3.2. & Болезни органов дыхания (среди женщин) & 30,07 & 19,58 & $-34,9 \%$ \\
\hline 4. & Болезни костно-мышечной системы (всего) & 14,24 & 12,81 & $-10,0 \%$ \\
\hline 4.1. & Болезни костно-мышечной системы (среди мужчин) & 14,5 & 12,75 & $-12,1 \%$ \\
\hline 4.2. & Болезни костно-мышечной системы (среди жен- & 13,95 & 12,89 & $-7,6 \%$ \\
\hline 5. & щин) & 10,15 & 6,18 & $-39,1 \%$ \\
\hline 5.1. & Травмы и отравления (всего) & 13,42 & 7,14 & $-46,8 \%$ \\
\hline 5.2. & Травмы и отравления (среди мужчин) & 6,55 & 4,74 & $-27,6 \%$ \\
\hline
\end{tabular}

По сравнению с 2008 годом в 2018 году в структуре случаев ЗВУТ отмечается:

- снижение случаев заболеваемости по болезням системы кровообращения на $8,2 \%$. Необходимо отметить, что общее снижение произошло в основном за счет мужчин (снижение у них $15,8 \%$ ), у женщин отмечается рост на $1,6 \%$;

- снижение случаев заболеваемости по органам дыхания на 46,5\%, у мужчин снижение на $54,4 \%$, у женщин - 34,8\%;

- снижение случаев заболеваемости костномышечной системы на $10 \%$, у мужчин снижение на $12,1 \%$, у женщин $-7,8 \%$;

- снижение случаев заболеваемости по травмам на $39,1 \%$ у мужчин снижение на $46,8 \%$, у женщин $-27,6 \%$;
При анализе случаев ЗВУТ по половому признаку в 2018 году отмечаются более высокие показатели у женщин, а в 2008 году были более высокие показатели у мужчин.

Среди показателей случаев ЗВУТ по нозологиям отмечается более высокие показатели среди женщин-работниц по заболеваниям органов дыхания и костно-мышечным заболеваниям, среди мужчин по заболеваниям органов кровообращения и травмам.

Выявление сезонности по случаям ЗВУТ. Наиболее значимые подъемы случаев заболеваемости у заболеваний органов дыхания и заболеваний костно-мышечной системы.

Таблица 6 Уровень дней ЗВУТ в 2008 и 2018 гг. по ведущим нозологиям (свод по «основным» предприятиям, на 100 работников, в т.ч. мужчин и женщин)

\begin{tabular}{|c|l|c|c|c|}
\hline \multicolumn{1}{|c|}{ Нозологии } & \multicolumn{1}{|c|}{ Но } & 2008 г. & 2018 г. & $\begin{array}{c}\text { Темп при- } \\
\text { роста }\end{array}$ \\
\hline 1. & \multicolumn{1}{|c|}{ Дни ЗВУТ (всего) } & 1225,85 & 831,51 & $-32,2 \%$ \\
\hline 1.1. & Дни ЗВУТ (среди мужчин) & 1261,33 & 831,17 & $-34,1 \%$ \\
\hline 1.2. & Дни ЗВУТ (среди женщин) & 1186,93 & 831,92 & $-29,9 \%$ \\
\hline 2. & Болезни органов кровообращения (всего) & 126,7 & 116,44 & $-8,1 \%$ \\
\hline 2.1. & Болезни органов кровообращения (среди мужчин) & 156,4 & 134,41 & $-14,1 \%$ \\
\hline 2.2 & Болезни органов кровообращения (среди женщин) & 94,11 & 89,80 & $-4,6 \%$ \\
\hline 3. & Болезни органов дыхания (всего) & 304,7 & 168,49 & $-44,7 \%$ \\
\hline 3.1. & Болезни органов дыхания (среди мужчин) & 291,2 & 141,46 & $-51,4 \%$ \\
\hline 3.2. & Болезни органов дыхания (среди женщин) & 319,5 & 208,51 & $-34,7 \%$ \\
\hline 4. & Болезни костно-мышечной системы (всего) & 215,2 & 193,47 & $-10,1 \%$ \\
\hline 4.1. & Болезни костно-мышечной системы (среди мужчин) & 210,9 & 193,22 & $-8,4 \%$ \\
\hline 4.2. & Болезни костно-мышечной системы (среди женщин) & 219,9 & 193,85 & $-11,8 \%$ \\
\hline 5. & Травмы и отравления (всего) & 199,8 & 136,37 & $-31,7 \%$ \\
\hline 5.1. & Травмы и отравления (среди мужчин) & 255,7 & 151,67 & $-40,7 \%$ \\
\hline 5.2. & Травмы и отравления (среди женщин) & 138,6 & 113,63 & $-18,0 \%$ \\
\hline
\end{tabular}

По сравнению с 2008 годом в 2018 году в структуре дней ЗВУТ отмечается:
- снижение дней заболеваемости по болезням системы кровообращения на $8,1 \%$. Необходимо отметить, что общее снижение произошло в основном 
за счет мужчин (снижение у них 14,1\%), у женщин отмечается снижение на 4,6\%;

- снижение дней заболеваемости по органам дыхания на 44,7\%, у мужчин снижение на 51,4\%, у женщин - 34,7\%;

- снижение дней заболеваемости костно-мышечной системы на $10,1 \%$, у мужчин снижение на $8,4 \%$, у женщин - $11,8 \%$;

- снижение дней заболеваемости по травмам на $31,7 \%$ у мужчин снижение на $40,7 \%$, у женщин $18 \%$;

При анализе дней ЗВУТ по половому признаку в 2008 году отмечались более высокие показатели у мужчин, а в 2018 году одинаковые показатели у мужчин и женщин.

Среди показателей дней ЗВУТ по нозологиям отмечается более высокие показатели среди женщин-работниц по заболеваниям органов дыхания, среди мужчин по заболеваниям органов кровообращения и травмам. Костно-мышечные заболевания в 2018 году равные показатели у мужчин и женщин.

Часто и длительно болеющий (ЧДБ) контингент (абсолютные данные). Часто и длительно болеющий контингент отбирается программой по факту 4 или более случаев получения листа трудоспособности или по длительности случая временной нетрудоспособности равной 40 и более дням

Таблица 7 Сравнение показателей часто и длительно болеющих по «основным» предприятиям в 2013 и 2018 гг. (абсолютные данные)

\begin{tabular}{|c|c|c|c|c|c|c|}
\hline \multirow[b]{2}{*}{ «Основные» предприятия } & \multicolumn{2}{|c|}{ Случаи } & \multirow{2}{*}{$\begin{array}{c}\text { Темп при- } \\
\text { роста }\end{array}$} & \multicolumn{2}{|c|}{ Дни } & \multirow{2}{*}{$\begin{array}{c}\text { Темп } \\
\text { прироста }\end{array}$} \\
\hline & 2013 г. & $\begin{array}{r}2018 \\
\Gamma .\end{array}$ & & $2013 \Gamma$. & 2018 г. & \\
\hline Литейный завод & 800 & 286 & $-64,3 \%$ & 44782 & 19773 & $-55,9 \%$ \\
\hline Кузнечный завод & 169 & 98 & $-42,0 \%$ & 9844 & 6801 & $-30,9 \%$ \\
\hline Прессово-рамный завод & 495 & 202 & $-59,2 \%$ & 31211 & 11887 & $-61,9 \%$ \\
\hline Завод двигателей & 405 & 213 & $-47,4 \%$ & 24665 & 11887 & $-51,8 \%$ \\
\hline Автомобильный завод & 483 & 375 & $-22,4 \%$ & 27985 & 26063 & $-6,9 \%$ \\
\hline Всего ЗВУТ ЧБД & 2352 & 1174 & $-50,1 \%$ & 138487 & 76411 & $-44,8 \%$ \\
\hline Общий ЗВУТ & 20664 & 13824 & & 307746 & 206661 & \\
\hline Доля ЧБД среди общего числа ЗВУТ & $11,4 \%$ & $8,5 \%$ & & $45,00 \%$ & $37,0 \%$ & \\
\hline
\end{tabular}

По итогам 2018 года среди часто и длительного контингента отмечается снижение случаев ЗВУТ на $64,3 \%$ и дней на 55,9\%. По предприятиям снижение случаев и дней не равномерное: наибольшая динамика в Прессово-рамном заводе и наименьшая в Автомобильном заводе. Необходимо обратить внимание, что часто и длительно болеющий контингент по случаям в общей структуре ЗВУТ занимает $8,5 \%$, а в днях $37 \%$, т.е. он формирует более трети дней временной нетрудоспособности.

В структуре случаев ЗВУТ ЧДБ контингента лидируют заболевания костно-мышечной системы, болезни органов дыхания, травмы и отравления и заболевания органов кровообращения. В структуре дней ЗВУБ ЧДБ контингента лидируют травмы и отравления, заболевания костно-мышечной системы, заболевания органов кровообращения, болезни органов дыхания, онкологические заболевания. Наиболее длительные по средней продолжительности 1 случая нетрудоспособности онкологические заболевания, болезни крови, травмы и отравления, инфекционные заболевания.

\section{Выводы:}

1. Одиннадцатилетняя динамика ЗВУТ указывает на сокращение случаев и дней ЗВУТ, средняя продолжительность 1 случая временной утраты трудоспособности также снизилась. Снижение случаев ЗВУТ в основном произошло за счет снижения заболеваний органов дыхания и травм.

2. При анализе случаев ЗВУТ по месяцам отмечаются подъемы в весенне-осенние периоды по заболеваниям органов дыхания и костно-мышечной системы. Выявляется определенная сезонность.

3. В структуре ЗВУТ в динамике отмечается снижение по всем заболеваниям, но заболевания системы кровообращения и костно-мышечной патологии имеют самую низкую динамику снижения. У женщин отмечается увеличение случаев ЗВУТ по сердечно-сосудистой патологии.

4. Часто и длительно болеющий контингент по случаям в общей структуре ЗВУТ занимает $8,5 \%$, а в днях $37 \%$, т.е. он формирует более трети дней временной нетрудоспособности. По итогам 2018 года среди часто и длительного контингента отмечается снижение случаев и дней ЗВУТ.

Список литературы:

1. Низамов И.Г. Заболеваемость с временной утратой трудоспособности и оптимизация управления охраной здоровья трудовых коллективов. Казань : Б. и., 1993. - 141,[2] с.

Адрес автора: 420100, г. Казань, ул. Ак. Глушко 3-52, artnag@mail.ru 